\title{
Preparation of Foot and Mouth Disease trivalent vaccine type A, O, SAT2 with determination of the Guinea pig protective dose 50 ( $\left(\right.$ PPD $_{50}$ )
}

\author{
Hind M. Daoud, Ehab El-Sayed Ibrahim, Wael Mossad Gamal El-Din and Amr Ismail Hassan Hassanin
}

Veterinary Serum and Vaccine Research Institute, Abbasia, Cairo, P.O.Box:131, Egypt, Fax: (202) 23428321 svri@idsc.gov.eg

Corresponding author: Ehab El-Sayed Ibrahim, email:ehabelsayed@hotmail.com

Received: 13-06-2013, Revised: 19-08-2013, Accepted: 20-08-2013, Published online: 23-09-2013

doi: 10.14202/vetworld.2013.844-851 How to cite this article: Daoud HM, I brahim EE, El-Din WMG, Hassanin AlH (2013) Preparation of Foot and Mouth Disease trivalent vaccine type A, O, SAT2 and determination of the Guinea pig protective dose $50\left(\mathrm{GPPD}_{50}\right)$, Veterinary World 6(11): 844-851.

\begin{abstract}
Aim: To determine the minimal effective dose of Foot and Mouth disease (FMD) serotypes (A, O, SAT2) according to antigenic content (146S) in order to produce a potent trivalent FMD vaccine.

Materials and Methods: Monovalent ISA 206 vaccines were prepared with 3 final concentration of 146S (1.6, 2.2, 2.8 $\mu \mathrm{g} / \mathrm{dose})$. The vaccine potency was evaluated by the determination of guinea pig protective dose $50\left(\mathrm{GPPD}_{50}\right)$ for each concentration of $146 \mathrm{~S}$ for each type of FMD monovalent vaccine where a fourfold dilution of the vaccines was constructed and each dilution was inoculated as $0.5 \mathrm{ml} \mathrm{S} / \mathrm{C}$ in each of 5 guinea pigs.

Results: The obtained results revealed that by using $1.6 \mu \mathrm{g}$ of $146 \mathrm{~S}$ for type O Pan Asia-2, A Iran O5 and SAT/EGY/2012, the $\mathrm{GPPD}_{50}$ was 40.4, 19.75 and 31.6 respectively, while the use of $2.2 \mu \mathrm{g}$ of $146 \mathrm{~S}$ resulted in $\mathrm{GPPD}_{50} 78.6,78.6$ and 105.8 for the three types respectively, and by using $2.8 \mu \mathrm{g}$ of $146 \mathrm{~S}$ resulted in $\mathrm{GPPD}_{50} 161.7,105.8$ and 161.7 for the three subtypes (A, O, SAT2) respectively. So it is clear that the lowest $146 \mathrm{~S}$ dilution inducing good protection (more than $72 \mathrm{GPPD}_{50}$ ) was $2.2 \mu \mathrm{g}$ for each serotype of used FMD monovalent vaccines. Depending on this result, the trivalent vaccine was formulated as $2.2 \mu \mathrm{g}$ of $146 \mathrm{~S}$ payload from each virus type/dose with equal volume of montanide ISA 206 oil as adjuvant. For more confirmation the prepared trivalent vaccine potency was evaluated by Guinea pig protective dose 50 which was found to be $88 \mathrm{GPPD}_{50}$. Also

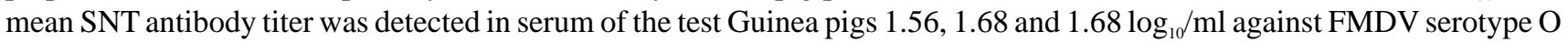
Pan Asia-2, A Iran O5 and SAT/EGY/2012 respectively in a higher level than the recommended protective titer (PT=1.2). Also for further confirmation the formulated trivalent vaccine which contain $2.2 \mu \mathrm{g} / \mathrm{serotype} / \mathrm{dose}$ were evaluated in cattle to measure the antibody titer against the three serotypes and the antibody against the three serotypes were found to be higher than

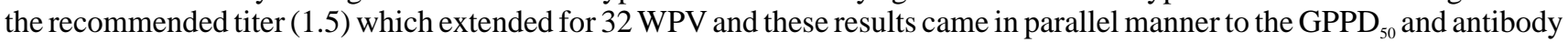
titer of the Guinea pigs of the prepared trivalent vaccine with $146 \mathrm{~S}(2.2 \mu \mathrm{g} / \mathrm{serotype} / \mathrm{dose})$.
\end{abstract}

Conclusion: It could be concluded that the minimum content of antigenic 146S of FMDV serotype O pan Asia, A Iran O5 and SAT2/EGY/2012 should not be less than $2.2 \mu \mathrm{g} / \mathrm{dose} /$ from each serotype in the trivalent vaccine aiming to induce the permissible protection in vaccinated livestock.

Keywords: $146 \mathrm{~S}$, cattle, FMD, GPPD ${ }_{50}$, guinea pigs, trivalent vaccine

\section{I ntroduction}

Foot and mouth disease (FMD) is an economically devastating disease of livestock. Although vaccines, available since the early 1900s, have been instrumental in eradicating FMD from parts of the world, the disease still affects millions of animals around the globe and remains the main sanitary barrier to the commerce of animals and animal products [1].

Although mortality is usually low, morbidity can reach $100 \%$ causing severe losses in production. Therefore, the disease remains a major economic concern for livestock-health in many developing countries and continued threat to disease free countries [2, 3].

The causative agent of FMD is a small positive sense ssRNA virus (approx. $8.3 \mathrm{~kb}$ ) which belongs to the Aphthovirus genus of the family Picornaviridae

Copyright: The authors. This article is an open access article licensed under the terms of the Creative Commons Attribution License (http://creativecommons.org/licenses/by/2.0) which permits unrestricted use, distribution and reproduction in any medium, provided the work is properly cited.
[4]. There are seven antigenically distinct serotypes of FMDV (A, O, C, South African Territories (SAT) types 1-3 and Asia-1) and each serotype has many subtype variants. This antigenic variation creates a major problem for the control of FMD, as infection or vaccination with one serotype of FMDV does not protect against other serotypes and may fail to protect fully against other subtypes within the same serotype [5].

Foot and mouth disease harvest contain three virus specific particles: (i) the infective $146 \mathrm{~S}$ virus particle, comprising one molecule of ss RNA and 60 copies of each of four polypeptides VP1,VP2,VP3 and VP4; (ii) the empty $75 \mathrm{~S}$ particles, devoid of RNA and comprising 60 copies of each of VP1,VP3 and VP0 (precursor of VP2 and VP4); (iii) the $12 \mathrm{~S}$ particle consisting of VP1,VP2 and VP3 but devoid of VP4 [6].

In Egypt, the disease is enzootic and outbreaks have been reported since 1950. FMD serotypes 'SAT2', 'A' and 'O' were reported in the years 2012, 1972 and 
2000, respectively [7-10]. Virus type 'O' was incriminated in the last two epidemic outbreaks, which occurred in 1987 and 1993.

Vaccination is the only approach to control FMD. The immunogenicity of foot and mouth disease (FMD) vaccines depends to a large extent on the production of whole virions (146S particles), in tissue culture and the stability of these particles after virus inactivation procedures and formulation into vaccines. [11].

The quantity of $146 \mathrm{~S}$ particles in inactivated FMD virus vaccine samples produced in FMD Vaccine Production Center is generally estimated by the sucrose gradient ultracentrifugation and optical density analysis by using the computer applying system [12].

The use of $146 \mathrm{~S}$ assay only or some serological tests which together increase the reliance on estimating potency of specific vaccine batch. They can also be assembled with an interconnected method which is based on the $146 \mathrm{~S}$ concentration of the final vaccine batch [13].

It is well known that vaccination is the basic step and corner stone in controlling FMD as other viral infectious diseases. The used vaccine in Egypt was the cell culture inactivated bivalent vaccine prepared from the local strain $\mathrm{O}_{1} / 3 / 1993$ and type A/1/EGY/ 2006). Nowadays and after isolation of the recent FMD O pan Asia, A Iran O5 [14] and SAT2/2012 [10] a new locally trivalent inactivated vaccine was generated containing the three types of the virus.

Vaccine manufacturers evaluate the efficiency of their vaccine according to the method which is defined in the European Pharmacopoeia. Regarding foot-andmouth disease (FMD) vaccine there are some difficulties to find animals for potency tests in the countries like Turkey where FMD is endemic and vaccine campaigns are carried out. In addition, potency tests must be carried out in containments having high biosecurity levels. There are many publications indicating a correlation between protections from virus challenge and neutralizing antibody response. However, up to now, none of the suggested method has been found valid [13].

Guinea pigs were chosen as experimental models to develop concepts and techniques to study the protective dose $50\left(\mathrm{PD}_{50}\right)$ of FMD vaccines because of the similarities of clinical symptoms in these animals to those of swine and cattle to saving cost [15, 16]. Guinea pigs are susceptible animals to FMD and can be protected by aqueous FMD vaccines. The methods of demonstrating the potency of such vaccines using Guinea pigs have been described having a good correlation with the protection afforded to cattle [17].

So the present work was designed to determine the minimal ideal dose of each of three monovalent FMD vaccines depending on its antigenic content (146S) and detection of vaccine potency which is expressed as $50 \%$ Guinea pig protective doses $\left(\mathrm{GPPD}_{50}\right)$ aiming to produce a potent trivalent vaccine which is evaluated as $\mathrm{GPPD}_{50}$, determination of antibodies in G. Pigs and cattle, so as to be safe and potent. In addition, determination of the optimal $146 \mathrm{~S}$ content aids to avoid the challenge of vaccinated animals during the vaccine evaluation test which may result in infection of animals with the virulent viral strains.

\section{Materials and Methods}

Experimental guinea pigs: Healthy adult male albino guinea pigs approximately of 400-500 gm body weight were used for preparation of guinea pig adapted FMD virus to be used for Guinea pig challenge and for determination of $\mathrm{GPPD}_{50}$ of the prepared vaccines.

Ethical approval: The experiment was as per the protocol of Institutional Animal Ethics Committee, the authors had taken permission of animal owners of private farm.

Tissue culture: Baby hamster kidney cell cultures $\left(\mathrm{BHK}_{21}\right)$ were obtained from the World Reference Lab. Pirbright Surrey, U.K. The cells were serially passaged and maintained with Minimum Essential Medium (MEM) modified with Hank's salt with 1-2 \% bovine serum in the FMD Research Department, Veterinary Serum and Vaccine Research Institute, Abbasia, Cairo [18].

\section{FMD Virus strains}

Tissue culture FMD virus: Local Foot and Mouth disease virus types O panAsia, A Iran O5 and SAT2/ EGY/2012were propagated in $\mathrm{BHK}_{21}$ cell line monolayer cultures for preparation of virus infected fluids in the Department of Foot and Mouth Diseases Research, Veterinary Serum and Vaccine Research Institute. The titer of the three types was expressed in $\log _{10} \mathrm{TCID}_{50}$ as described earlier [19] and the CF was carried out according to earlier reports [20,21].

Guinea pig adapted virus: Albino Guinea pigs were inoculated by FMD virus strain O pan Asia-2, A Iran O5 and SAT2 / EGY/2012 intradermoplanter in the metatarsal pads. After 24-48 hours the developed lesions were collected aseptically. The lesions extract was again re-inoculated in other Guinea pigs 5 times until the virus became quite adapted to Guinea pigs as recommended earlier [22].

Virus purification: Aseptically, the harvested culture medium from FMD virus infected $\mathrm{BHK}_{21}$ cell cultures were centrifuged in a cooling centrifuge at $7000 \mathrm{rpm}$ for 20 minutes to remove cell debris [23].

\section{Virus inactivation}

Each FMD virus $\left(\mathrm{O}, \mathrm{A}\right.$ and SAT2) of the $7^{\text {th }}$ passage on BHK monolayer with an infectivity titer of $10^{8} \mathrm{TCID}_{50}$ /dose was treated with $1.5 \%$ chloroform then the inactivation occur by using combination of BEI $1 \mathrm{mM}$ and $0.04 \%$ FA (BEI-FA) according to the method described previously $[24,25] .2 \%$ of each of 
sodium thiosulphate $(20 \%)$ and sodium bisulphite (20\%) were added after inactivation process to neutralize the excess of BEI and formalin.

\section{Concentration of the FMD virus serotypes}

The tissue culture viral fluids of the three serotypes (O pan Asia-2, A Iran O5 and SAT2/ EGY/ 2012) were centrifuged at 7000 revolution/ minute for 30 minutes and then concentrated by PEG-6000 to reach to $1 / 10$ of its original volume.

\section{Estimation of antigenic content (Total protein and} 146S) in FMD virus types

Protein estimation of FMD prepared antigen was performed by Bradford's method.The concentration of $146 \mathrm{~S}$ particles in the virus preparation was estimated by using sucrose density gradient ultracentrifugation by determining the absorbance at $254 \mathrm{~nm}$ using ISCO 520 C Density Gradient system as described previously $[26,27]$.

\section{Formulation of FMD vaccine with Montanide ISA 206}

Vaccine formulation was done according to the method described earlier [28, 29] as follows: The oil phase consisted of Montanide ISA 206, mixed as equal parts of an aqueous and oil phase weight/weight, and mixed thoroughly.

Each of FMD monovalent vaccines was prepared with three concentrations of $146 \mathrm{~S}$ finally adjusted to be $1.6 \mu \mathrm{g}, 2.2 \mu \mathrm{g}$, and $2.8 \mu \mathrm{g}$ viral particles/dose/serotype.

Trivalent FMD oil vaccine was formulated from minimum concentration of $146 \mathrm{~S}$ from each serotype which gave a high GPPD ${ }_{50}$.

\section{Potency test of prepared vaccines}

It was carried out through determination of the Guinea pigs protection dose $50\left(\mathrm{GPPD}_{50}\right)$ according to earlier reports $[17,30]$ where Guinea pigs were divided into 10 groups as following:

* Each of the $1^{\text {st }}$ three groups was vaccinated with FMD (O pan Asia-2) with either concentration of $146 \mathrm{~S}$, using four fold dilution from such vaccine (undiluted, 1/4, 1/16, 1/64, 1/256). Each dilution was inoculated as $0.5 \mathrm{ml} \mathrm{S/C}$ in each of 5 Guinea pigs.

* Each of the $2^{\text {nd }}$ three groups was vaccinated with FMD (A Iran O5) in the same manner as FMD (O pan Asia-2).

* Each of the $3^{\text {rd }}$ three groups was vaccinated with FMD (SAT2/EGY/2012) in the same manner as FMD (O pan Asia-2).

* The $4^{\text {th }}$ group contained 5 Guinea pigs were kept as non vaccinated control group.

After 3 weeks, all Guinea pigs in all groups were challenged with its specific Guinea pig adapted FMD virus; by inoculation intra-dermoplanter. The challenged Guinea pigs were observed for 7 days till generalization of infection.

The $\mathrm{GPPD}_{50}$ was calculated according to previous reports [16,19,22]. The Guinea pigs were checked after
4-5 days of the challenge test for the development of primary and secondary lesions. If the virus generalizes in the guinea pig's body, the vesicles on the uninoculated feet and the tongue are observed for a positive reaction to the FMDV infection in guinea pigs. The observations were recorded and the Protection Dose50 $\left(\mathrm{PD}_{50}\right)$ was calculated in all groups and the control groups.

\section{Preparation of trivalent FMD vaccine}

The trivalent FMD vaccine (containing serotypes O pan Asia-2, A Iran O5 and SAT2/Egy/2012) with Montanide ISA 206 was formulated from the lowest concentration of 146S from each serotype yielding high protective $\mathrm{GPPD}_{50}$ through the first part of the present work. This vaccine was inoculated as $0.5 \mathrm{ml}$ in each of 5 groups of Guinea pigs and each group was challenged with one of the FMD viral serotype (either O pan Asia-2 or A Iran O5 or SAT2/EGY/2012) after 4 weeks. Serum samples were collected pre-vaccination and weekly for 4 weeks post vaccination. Serum neutralization test was performed on the serum samples as described earlier [31] and the antibody titer was expressed as $\log _{10}$.

\section{Field application to the prepared trivalent FMD oil vaccine in cattle farm}

In Fayoum governorate, cattle farm was vaccinated with the experimental trivalent FMD oil vaccine batch to determine the efficacy and the duration of immune response which induced with the prepared vaccine according to its $146 \mathrm{~S}$ concentration. Serum neutralization test was performed on the serum samples as described earlier [31] and the antibody titer was expressed as $\log _{10}$.

\section{Results and Discussion}

FMD is still represent a non neglectable problem in livestock in many countries resulted in huge economic loses especially developing countries. Regarding Egypt several outbreaks attack the country due to the infection with either type O, A, SAT2 [7]. Through the last years monovalent FMD vaccine type $\mathrm{O}$ was used for several years where it was the only recorded type in Egypt [32], after that and according to the introduction of type A, bivalent vaccine was successfully prepared containing both type $\mathrm{O}$ and $\mathrm{A}[8$, 28, 29, 30,33]. More recently FMDV type SAT2 was recorded in Egypt $[10,34]$ and this required the preparation of a trivalent vaccine containing the three present serotypes (A, O, SAT2). So, the present study was planned as a preliminary work to establish such vaccine through the determination of the minimal $146 \mathrm{~S}$ content of each used serotype inducing the highest $\mathrm{GPPD}_{50}$.

The concentration of antigen per dose indirectly determines the duration of immunity. Further, the quantity of antibody induced and particularly, initial magnitude of the immune response determines the 
Table-1. FMD virus titer, CF value, total protein and 146S concentration

\begin{tabular}{lccccc}
\hline FMD virus types & Titer $\left(\log _{\mathbf{1 0}}\right.$ TCID50/ml) & CFT Value & Total protein $(\mathbf{m g} / \mathbf{m l})$ & $\mathbf{1 4 6 S}(\boldsymbol{\mu g} / \mathbf{m l})$ & $\mathbf{1 4 6 S}$ after concentration $(\boldsymbol{\mu g} / \mathbf{m l})$ \\
\hline O Pan Asia-2 & 8.5 & 64 & 3.8 & 4 & 5.7 \\
A Iran O5 & 9 & 32 & 3.7 & 3.5 & 5.2 \\
SAT-2/Egy. 2012 & 8.8 & 32 & 3.5 & 3 & 4.8 \\
\hline
\end{tabular}

Table-2. $\mathrm{GPPD}_{50}$ of FMD virus type $\mathrm{O}$ panAsia- 2 with different $146 \mathrm{~S}$ content vaccine

\begin{tabular}{|c|c|c|c|c|c|c|c|c|c|c|c|c|c|c|c|c|c|c|}
\hline \multirow{2}{*}{$\begin{array}{l}\text { Vaccine } \\
\text { dilution }\end{array}$} & \multicolumn{3}{|c|}{ VG } & \multicolumn{3}{|c|}{ PG } & \multicolumn{3}{|c|}{ NPG } & \multicolumn{3}{|c|}{ CPG } & \multicolumn{3}{|c|}{ CNPG } & \multicolumn{3}{|c|}{ Protection \% } \\
\hline & $1.6^{*}$ & $2.2^{*}$ & $2.8^{*}$ & $1.6^{*}$ & $2.2^{*}$ & $2.8^{*}$ & $1.6^{*}$ & $2.2^{*}$ & $2.8^{*}$ & $1.6^{*}$ & $2.2^{*}$ & $2.8^{*}$ & $1.6^{*}$ & $2.2^{*}$ & $2.8^{*}$ & $1.6^{*}$ & $2.2^{*}$ & $2.8^{*}$ \\
\hline Un diluted & 5 & 5 & 5 & 5 & 5 & 5 & 0 & 0 & 0 & 16 & 18 & 21 & 0 & 0 & 0 & 100 & 100 & 100 \\
\hline & 5 & 5 & 5 & 5 & 5 & 5 & 0 & 0 & 0 & 11 & 13 & 16 & 0 & 0 & 0 & 100 & 100 & 100 \\
\hline $1 / 16$ & 5 & 5 & 5 & 4 & 4 & 5 & 1 & 1 & 0 & 6 & 8 & 11 & 1 & 1 & 0 & 85.7 & 88.8 & 100 \\
\hline $1 / 64$ & 5 & 5 & 5 & 2 & 3 & 4 & 3 & 2 & 1 & 2 & 4 & 6 & 4 & 3 & 1 & 33.3 & 57.1 & 85.7 \\
\hline $1 / 256$ & 5 & 5 & 5 & 0 & 1 & 2 & 5 & 4 & 3 & 0 & 1 & 2 & 9 & 7 & 4 & 0 & 12.5 & 33.3 \\
\hline
\end{tabular}

VG: No. of vaccinated guinea pigs, PG: No. of protected guinea pigs, NPG: No. of non protected guinea pigs, CPG: Cumulative no. of protected guinea pigs, CNPG: Cumulative no. of non protected guinea pigs, $(* 146 \mathrm{~S} \mu \mathrm{g} / \mathrm{ml}), \mathrm{GPPD}_{50}\left(1.6 \mu \mathrm{g} 146 \mathrm{~S}\right.$ of O) $=40.6, \mathrm{GPPD}_{50}(2.2 \mu \mathrm{g} 146 \mathrm{~S}$ of O) $=$ $78.6 \mathrm{GPPD}_{50}(2.8 \mu \mathrm{g} 146 \mathrm{~S}$ of $\mathrm{O})=161.7$

Table-3 GPPD $_{50}$ of FMD virus type A Iran 05 with different $146 \mathrm{~S}$ content vaccine.

\begin{tabular}{|c|c|c|c|c|c|c|c|c|c|c|c|c|c|c|c|c|c|c|}
\hline \multirow{2}{*}{$\begin{array}{l}\text { Vaccine } \\
\text { dilution }\end{array}$} & \multicolumn{3}{|c|}{ VG } & \multicolumn{3}{|c|}{ PG } & \multicolumn{3}{|c|}{ NPG } & \multicolumn{3}{|c|}{ CPG } & \multicolumn{3}{|c|}{ CNPG } & \multicolumn{3}{|c|}{ Protection \% } \\
\hline & $1.6^{*}$ & $2.2^{*}$ & $2.8^{*}$ & $1.6^{*}$ & $2.2^{*}$ & $2.8^{*}$ & $1.6^{*}$ & $2.2^{*}$ & $2.8^{*}$ & $1.6^{*}$ & $2.2^{*}$ & $2.8^{*}$ & $1.6^{*}$ & $2.2^{*}$ & $2.8^{*}$ & $1.6^{*}$ & $2.2^{*}$ & $2.8^{*}$ \\
\hline Un diluted & 5 & 5 & 5 & 5 & 5 & 5 & 0 & 0 & 0 & 13 & 18 & 19 & 0 & 0 & 0 & 100 & 100 & 100 \\
\hline & 5 & 5 & 5 & 4 & 5 & 5 & 1 & 0 & 0 & 8 & 13 & 14 & 1 & 0 & 0 & 88.8 & 100 & 100 \\
\hline $1 / 16$ & 5 & 5 & 5 & 3 & 4 & 4 & 2 & 1 & 1 & 4 & 8 & 9 & 3 & 1 & 1 & 57.1 & 88.8 & 90 \\
\hline $1 / 64$ & 5 & 5 & 5 & 1 & 3 & 4 & 4 & 2 & 1 & 1 & 4 & 5 & 7 & 3 & 2 & 12.5 & 57.1 & 71.4 \\
\hline $1 / 256$ & 5 & 5 & 5 & 0 & 1 & 1 & 5 & 4 & 4 & 0 & 1 & 1 & 12 & 7 & 6 & 0 & 12.5 & 14.2 \\
\hline
\end{tabular}

VG: No. of vaccinated guinea pigs, PG: No. of protected guinea pigs, NPG: No. of non protected guinea pigs, CPG: Cumulative no. of protected guinea pigs, CNPG: Cumulative no. of non protected guinea pigs, $(* 146 \mathrm{~S} \mu \mathrm{g} / \mathrm{ml}), \operatorname{GPPD}_{50}\left(1.6 \mu \mathrm{g} 146 \mathrm{~S}\right.$ of A) $=19.75, \mathrm{GPPD}_{50}(2.2 \mu \mathrm{g} 146 \mathrm{~S}$ of $\mathrm{A})$ $=78.6, \mathrm{GPPD}_{50}(2.8 \mu \mathrm{g} 146 \mathrm{~S}$ of $\mathrm{A})=105.8$

Table-4. GPPD ${ }_{50}$ of FMD virus type SAT2/EGY/2012 with different $146 \mathrm{~S}$ content vaccine

\begin{tabular}{|c|c|c|c|c|c|c|c|c|c|c|c|c|c|c|c|c|c|c|}
\hline \multirow{2}{*}{$\begin{array}{l}\text { Vaccine } \\
\text { dilution }\end{array}$} & \multicolumn{3}{|c|}{ VG } & \multicolumn{3}{|c|}{ PG } & \multicolumn{3}{|c|}{ NPG } & \multicolumn{3}{|c|}{ CPG } & \multicolumn{3}{|c|}{ CNPG } & \multicolumn{3}{|c|}{ Protection \% } \\
\hline & $1.6^{*}$ & $2.2^{*}$ & $2.8^{*}$ & $1.6^{*}$ & $2.2^{*}$ & $2.8^{*}$ & $1.6^{*}$ & $2.2^{*}$ & $2.8^{*}$ & $1.6^{*}$ & $2.2^{*}$ & $2.8^{*}$ & $1.6^{*}$ & $2.2^{*}$ & $2.8^{*}$ & $1.6^{*}$ & $2.2^{*}$ & $2.8^{*}$ \\
\hline Un diluted & 5 & 5 & 5 & 5 & 5 & 5 & 0 & 0 & 0 & 15 & 19 & 21 & 0 & 0 & 0 & 100 & 100 & 100 \\
\hline $1 / 4$ & 5 & 5 & 5 & 5 & 5 & 5 & 0 & 0 & 0 & 10 & 14 & 16 & 0 & 0 & 0 & 100 & 100 & 100 \\
\hline $1 / 16$ & 5 & 5 & 5 & 4 & 4 & 5 & 1 & 1 & 0 & 5 & 9 & 11 & 1 & 1 & 0 & 83.3 & 90 & 100 \\
\hline $1 / 64$ & 5 & 5 & 5 & 1 & 4 & 4 & 4 & 1 & 1 & 1 & 5 & 6 & 5 & 2 & 1 & 16.6 & 71.4 & 85.7 \\
\hline $1 / 256$ & 5 & 5 & 5 & 0 & 1 & 2 & 5 & 4 & 3 & 0 & 1 & 2 & 10 & 6 & 4 & 0 & 14.3 & 33.3 \\
\hline
\end{tabular}

VG: No. of vaccinated guinea pigs, PG: No. of protected guinea pigs, NPG: No. of non protected guinea pigs, CPG: Cumulative no. of protected guinea pigs, CNPG: Cumulative no. of non protected guinea pigs, $(* 146 \mathrm{~S} \mu \mathrm{g} / \mathrm{ml}), \mathrm{GPPD}_{50}\left(1.6 \mu \mathrm{g} 146 \mathrm{~S}\right.$ of SAT2) $=31.6, \mathrm{GPPD}_{50}(2.2 \mu \mathrm{g} 146 \mathrm{~S}$ of $\mathrm{SAT2})=105.8, \mathrm{GPPD}_{50}(2.8 \mu \mathrm{g} 146 \mathrm{~S}$ of SAT2 $)=161.7$

duration of effective immunity.

It is well established that the major immunogenic component of the FMDV is the intact $146 \mathrm{~S}$ particle or antigen payload [35].

The obtained result revealed that the virus titers of the FMDV serotypes (O Pan Asia-2, A Iran O5 and SAT/EGY/2012) were 8.5, 9and $8.8 \log _{10}$ TCID $_{50} / \mathrm{ml}$ with CFT value of 64,32 and 32 ; total protein of the FMDV $3.8,3.7$ and $3.5 \mathrm{mg} / \mathrm{ml}$ and $146 \mathrm{~S}$ antigenic content $4,3.5$ and $3 \mu \mathrm{g} / \mathrm{ml}$ before the concentration respectively but the $146 \mathrm{~S}$ was reached to $5.7,5.2$ and $4.8 \mu \mathrm{g} / \mathrm{ml}$ after concentration with PEG as tabulated in Table-1. As vaccine preparation procedure described earlier $[14,36]$, where it was mentioned that infectivity of FMD virus samples was determined by cell culture methods. All of the virus samples were inoculated on BHK $_{21}$ cells; also, their titration was obtained by $\mathrm{TCID}_{50}$ methods. The antigenicity of the virus samples were studied by the Complement Fixation Test (CFT).
The $\mathrm{GPPD}_{50}$ was estimated to determine the protective dose for Guinea pigs from each $146 \mathrm{~S}$ concentration $(1.6 \mu \mathrm{g}, 2.2 \mu \mathrm{g}$ and $2.8 \mu \mathrm{g})$ for each serotype of FMDV. It was found that using $1.6 \mu \mathrm{g}$ of $146 \mathrm{~S}$, the $\mathrm{GPPD}_{50}$ was $40.4,19.75$ and 31.6 for (O Pan Asia-2, A Iran O5 and SAT/EGY/2012) respectively, while using $2.2 \mu \mathrm{g}$, the $\mathrm{GPPD}_{50}$ was 78.6, 78.6 and105 for O Pan Asia-2, A Iran O5 and SAT/EGY/2012) respectively, but using $2.8 \mu \mathrm{g}$ of $146 \mathrm{~S}$, induced $\mathrm{GPPD}_{50}$ was $161.7,105.8$ and 161.7 for O Pan Asia-2, A Iran O5 and SAT/EGY/2012 respectively. These results are tabulated in Table-2, 3, 4, and 5. These results were in agreement with earlier report [37] which used same FMD vaccine virus where in $2.2 \mu \mathrm{g}$ of the antigen was required to obtain 1 PD50 although, protection was observed even with lower antigen dose. On the other side, these results disagree with another report [38] who mentioned that many trials have been conducted to correlate the quantity of $146 \mathrm{~S}$ virus particles per 
Table-5. GPPD 50 of different $146 \mathrm{~S}$ concentrations of FMD virus serotypes and mean serum neutralizing antibody after 28 day post vaccination in Guinea pigs

\begin{tabular}{|c|c|c|c|}
\hline Types of FMD virus & $146 S$ conc. $(\mu \mathrm{g} / \mathrm{ml})$ & GPPD50 & $\begin{array}{c}\text { Mean serum neutralizing antibody after } 28 \text { day post } \\
\text { vaccination in Guinea pigs }\end{array}$ \\
\hline FMDV type O panAsia-2 & $\begin{array}{l}1.6 \\
2.2 \\
2.8\end{array}$ & $\begin{array}{c}40.6 \\
78.6 \\
161.7\end{array}$ & $\begin{array}{c}0.9 \\
1.6 \\
1.84\end{array}$ \\
\hline FMDV type A Iran O5 & $\begin{array}{l}1.6 \\
2.2 \\
2.8\end{array}$ & $\begin{array}{c}19.75 \\
78.6 \\
105.8\end{array}$ & $\begin{array}{c}0.7 \\
1.55 \\
1.75\end{array}$ \\
\hline FMDV type SAT2 /Egy/2012 & $\begin{array}{l}1.6 \\
2.2 \\
2.8\end{array}$ & $\begin{array}{c}31.6 \\
105.8 \\
161.7\end{array}$ & $\begin{array}{c}0.7 \\
1.7 \\
1.86\end{array}$ \\
\hline
\end{tabular}

$\mathrm{GPPD}_{50}$ consider protective if it is more than 72 [22], The protective SN antibody is 1.2 [36]

Table-6. GPPD ${ }_{50}$ of trivalent FMD vaccine (type O panAsia-2, A I ranO5 and SAT2/EGY/2012)

\begin{tabular}{lccccc}
\hline Vaccine dilution & No. of G uinea pigs & No. of survived & No. of affected & CS & CA \\
\hline Undiluted & 5 & 5 & 0 & 18 & 0 \\
$1 / 4$ & 5 & 5 & 0 & 13 & $100 \%$ \\
$1 / 16$ & 5 & 4 & 1 & 8 & 1 \\
$1 / 64$ & 5 & 4 & 5 & 4 & 2 \\
$1 / 256$ & 5 & 0 & $58 \%$ & 0 & 7 \\
\hline
\end{tabular}

$\mathrm{GPPD}_{50}=88$

vaccine dose and the protection and immunity achieved. The minimum effective dose of purified FMDV A-119 required for eliciting virus-neutralizing immune response in guinea pigs was about $1.6 \mu \mathrm{g}$. This disagreement could be attributed to the different subtype of FMDV type A used in this experiment.

Also as in Table-5, the mean neutralizing antibody titer of the Guinea pigs vaccinated with FMD vaccine with $1.6,2.2,2.8 \mu \mathrm{g}$ indicated that the neutralizing antibody was protected using $146 \mathrm{~S} 2.2$ and $2.8 \mu \mathrm{g} / \mathrm{ml}$ with all serotype while the SNT was 0.9 , 0.7 and 0.7 using $1.6 \mu \mathrm{g} / \mathrm{ml}$ of $146 \mathrm{~S}$ for (O Pan Asia-2, A Iran O5 and SAT/EGY/2012) respectively but it was $1.6,1.55,1.7 \mathrm{using} 2.2 \mu \mathrm{g} / \mathrm{ml}$ of $146 \mathrm{~S}$ for (O Pan Asia2, A Iran O5 and SAT/EGY/2012) respectively also it was $1.84,1.75,1.86$ using $2.8 \mu \mathrm{g} / \mathrm{ml}$ of $146 \mathrm{~S}$ for (O Pan Asia-2, A Iran O5 and SAT/EGY/2012) respectively. These findings are in agreement with previous report [36] that showed that the protective titer of SNT in Guinea pigs is 1.2.

The above mentioned results indicate that the lowest concentration of $146 \mathrm{~S}$ which resulted in good protection; through determination of $\mathrm{GPPD}_{50}$ (more than 72 as mentioned earlier [39]); was $2.2 \mu \mathrm{g}$ for each serotype (O Pan Asia-2, A Iran O5 and SAT/ EGY/ 2012).

The new formulated prepared vaccine as $2.2 \mu \mathrm{g}$ of $146 \mathrm{~S}$ payload from each virus type with equal volume from the oil was diluted (undiluted, 1/4, 1/16, 1/64, 1/256) and each dilution was inoculated in each of 5 Guinea pigs. The obtained GPPD $_{50}$ was found to be 88 as shown in Table-6. Such obtained GPPD50 appeared to be higher than the recommended one, the thing that confirms the high potency of the prepared vaccine.

Testing of Guinea pigs serum samples, to confirm the results of $\mathrm{GPPD}_{50}$ using SNT, showed antibody titers of 1.56, 1.68 and $1.68 \log _{10} / \mathrm{ml}$ against FMDV serotype O Pan Asia-2, A Iran O5 and SAT/EGY/2012 respectively. Such titers appear to be higher than the recommended protective titer (1.2). These results indicate that the prepared trivalent FMD vaccine able to induce acceptable immune level in vaccinated Guinea pigs where the obtained antibody titers against the three types were found to be higher than the recommended titer $(\mathrm{PT}=1.2)$ coming in a parallel manner to that of GPPD 50 . These finding coming in agreement with those of earlier report [36] who found that after the vaccines were inoculated subcutaneously on the back foot in two groups of guinea pigs, just two of ten animals showed antiserum titration above the protective titer $(\mathrm{PT}=1.2)$, and the other 8 animals were below the PT.

Finally we used the Guinea pigs as model for vaccine evaluation instead of cattle to lower the cost during the vaccine evaluation, so to confirm these results we made field application to the experimental prepared vaccine to confirm that the amount of $146 \mathrm{~S}$ used is sufficient to protect cattle from FMDV, as shown in Table- 8 , the serum neutralizing antibody titer against the three serotypes (A,O,SAT) in cattle for 36 week post vaccination (WPV). The results were confirmatory to the previous results as the SN antibody titer against serotype $(\mathrm{O})$ started as 0.3 at $0 \mathrm{WPV}$ and reached its maximum antibody level at 10WPV (3.15) and extended as a protective $\mathrm{SN}$ antibody titer from 2 to 32 WPV while the antibody titer against serotype (A) started as 0.3 at $0 \mathrm{WPV}$ and reached its maximum titer at 8,10 and $12 \mathrm{WPV}$, the protective (1.5) extended from 2 to 34WPV. The SN antibody titer against FMDV serotype (SAT) was zero at $0 \mathrm{WPV}$ and reached its maximum antibody titer (3.15) at $10 \mathrm{WPV}$, the protective antibody titer (1.5) extended from 2 to 32 WPV. From these results, the antibody titer against the three serotypes were found to be higher than the recommended titer (1.5) which extended for $32 \mathrm{WPV}$ and these results came in parallel manner to the $\mathrm{GPPD}_{50}$ 
Table-7. FMD serum neutralizing antibody titters in Guinea pigs vaccinated with trivalent FMD inactivated ISA 206 oil vaccine

\begin{tabular}{|c|c|c|c|c|c|c|c|c|c|c|c|c|c|c|c|c|}
\hline \multirow{3}{*}{$\begin{array}{l}\text { Animals } \\
\text { group }\end{array}$} & \multicolumn{15}{|c|}{ FMD serum neutralizing antibody titer $(\log 10 / \mathrm{mL})$} & \multirow[t]{3}{*}{ Challenge } \\
\hline & \multicolumn{3}{|c|}{ O WPV* } & \multicolumn{3}{|c|}{1 WPV } & \multicolumn{3}{|c|}{ 2WPV } & \multicolumn{3}{|c|}{ 3WPV } & \multicolumn{3}{|c|}{ 4WPV } & \\
\hline & A & 0 & SAT2 & A & 0 & SAT2 & A & 0 & SAT2 & A & 0 & SAT2 & A & 0 & SAT2 & \\
\hline 1 & 0.3 & - & - & 0.75 & - & - & 1.2 & - & - & 1.5 & - & - & 1.65 & - & - & $A$ \\
\hline 2 & 0.15 & - & - & 0.6 & - & - & 0.9 & - & - & 1.35 & - & - & 1.5 & - & - & $A$ \\
\hline 3 & 0.3 & - & - & 0.9 & - & - & 1.05 & - & - & 1.35 & - & - & 1.5 & - & - & $A$ \\
\hline 4 & 0.3 & - & - & 0.9 & - & - & 1.35 & - & - & 1.5 & - & - & 1.65 & - & - & $A$ \\
\hline 5 & 0.15 & - & - & 0.6 & - & - & 1.05 & - & - & 1.35 & - & - & 1.5 & - & - & $A$ \\
\hline Mean & 0.24 & - & - & 0.75 & - & - & 1.11 & - & - & 1.41 & - & - & 1.56 & - & - & \\
\hline 6 & - & 0.45 & - & - & 0.9 & - & - & 1.35 & - & - & 1.65 & - & - & 1.8 & - & 0 \\
\hline 7 & - & 0.3 & - & - & 0.6 & - & - & 1.05 & - & - & 1.5 & - & - & 1.65 & - & 0 \\
\hline 8 & - & 0.3 & - & - & 0.6 & - & - & 1.05 & - & - & 1.35 & - & - & 1.65 & - & 0 \\
\hline 9 & - & 0.45 & - & - & 0.9 & - & - & 1.35 & - & - & 1.35 & - & - & 1.5 & - & 0 \\
\hline 10 & - & 0.3 & - & - & 0.75 & - & - & 1.2 & - & - & 1.5 & - & - & 1.8 & - & 0 \\
\hline Mean & - & 0.36 & - & - & 0.75 & - & - & 1.2 & - & - & 1.47 & - & - & 1.68 & - & - \\
\hline 11 & - & - & 0.15 & - & - & 0.6 & - & - & 1.05 & - & - & 1.35 & - & - & 1.65 & SAT-2 \\
\hline 12 & - & - & 0.3 & - & - & 0.75 & - & - & 1.2 & - & - & 1.35 & - & - & 1.5 & SAT-2 \\
\hline 13 & - & - & 0.3 & - & - & 0.75 & - & - & 1.2 & - & - & 1.5 & - & - & 1.65 & SAT2 \\
\hline 14 & - & - & 0.3 & - & - & 0.9 & - & - & 1.35 & - & - & 1.65 & - & - & 1.8 & SAT-2 \\
\hline 15 & - & - & 0.45 & - & - & 0.9 & - & - & 1.35 & - & - & 1.65 & - & - & 1.8 & SAT-2 \\
\hline Mean & - & - & 0.3 & - & - & 0.78 & - & - & 1.23 & - & - & 1.5 & - & - & 1.68 & - \\
\hline 16 & 0.45 & - & - & 0.45 & - & - & 0.45 & - & - & 0.3 & - & - & 0.3 & - & - & $A$ \\
\hline 17 & 0.3 & - & - & 0.3 & - & - & 0.3 & - & - & 0.3 & - & - & 0.3 & - & - & A \\
\hline 18 & 0.3 & - & - & 0.3 & - & - & 0.3 & - & - & 0.3 & - & - & 0.3 & - & - & A \\
\hline 19 & - & 0.3 & - & - & 0.3 & - & - & 0.3 & - & - & 0.3 & - & - & 0.3 & - & O \\
\hline 20 & - & 0.3 & - & - & 0.3 & - & - & 0.3 & - & - & 0.3 & - & - & 0.3 & - & 0 \\
\hline 21 & - & 0.3 & - & - & 0.3 & - & - & 0.3 & - & - & 0.3 & - & - & 0.3 & - & $\mathrm{O}$ \\
\hline 22 & - & - & 0.15 & - & - & 0.15 & - & - & 0.15 & - & - & 0.15 & - & - & 0.15 & SAT-2 \\
\hline 23 & - & - & 0.3 & - & - & 0.3 & - & - & 0.3 & - & - & 0.3 & - & - & 0.3 & SAT-2 \\
\hline 24 & - & - & 0.3 & - & - & 0.3 & - & - & 0.3 & - & - & 0.3 & - & - & 0.3 & SAT2 \\
\hline 25 & 0.3 & 0.3 & 0.3 & 0.3 & 0.3 & 0.3 & 0.3 & 0.3 & 0.3 & 0.3 & 0.3 & 0.3 & 0.3 & 0.3 & 0.3 & - \\
\hline 26 & 0.3 & 0.3 & 0.3 & 0.3 & 0.3 & 0.3 & 0.3 & 0.3 & 0.3 & 0.3 & 0.3 & 0.3 & 0.3 & 0.3 & 0.3 & - \\
\hline 27 & 0.45 & 0.15 & 0.3 & 0.45 & 0.15 & 0.3 & 0.45 & 0.15 & 0.3 & 0.45 & 0.15 & 0.3 & 0.45 & 0.15 & 0.3 & - \\
\hline
\end{tabular}

* WPV: Weeks post vaccination; 1 -5 vaccinated with trivalent FMD oil vaccine and challenged with FMDV type A after 4 WPV; 6 - 10 vaccinated with trivalent FMD oil vaccine and challenged with FMDV type $O$ after 4WPV; $11-15$ vaccinated with trivalent FMD oil vaccine and challenged with FMDV type SAT2 after 4WPV; 16-18 control positive inoculated with FMDV type A; 19-21 control positive inoculated with FMDV type O 22-24 control positive inoculated with FMDV type SAT2; 25-27 control negative non vaccinated non infected Guinea Pigs

Table-8. Mean FMD serum neutralizing antibody titters in cattle vaccinated with trivalent FMD inactivated ISA 206 oil vaccine

\begin{tabular}{lccc}
\hline Weeks post vaccination & \multicolumn{3}{c}{ Mean FMD serum neutralizing antibody titer in cattle farm } \\
\cline { 2 - 4 } & $\mathbf{0}$ & $\mathbf{A}$ & SAT-2 \\
\hline 0 & 0.3 & 0.3 & 0.0 \\
1 & 1.2 & 1.2 & 1.05 \\
2 & 1.8 & 1.8 & 1.5 \\
3 & 2.1 & 2.1 & 1.8 \\
4 & 2.4 & 2.55 & 2.1 \\
6 & 2.8 & 2.8 & 2.4 \\
8 & 3 & 3.15 & 2.85 \\
10 & 3.15 & 3.15 & 3.15 \\
12 & 3.0 & 3.15 & 3.0 \\
14 & 2.7 & 2.85 & 2.85 \\
16 & 2.55 & 2.7 & 2.7 \\
18 & 2.55 & 2.4 & 2.55 \\
20 & 2.25 & 2.4 & 2.25 \\
22 & 2.1 & 2.25 & 2.1 \\
24 & 2.1 & 2.1 & 1.8 \\
26 & 1.95 & 1.8 & 1.8 \\
28 & 1.8 & 1.8 & 1.8 \\
30 & 1.65 & 1.65 & 1.65 \\
32 & 1.5 & 1.65 & 1.5 \\
34 & 1.35 & 1.5 & 1.3 \\
36 & 1.2 & 1.35 & \\
\hline
\end{tabular}

Antibody titer expressed in $\log _{10}$; Protective SN antibody titer is 1.5 [14]

and antibody titer of the Guinea pigs of the prepared trivalent vaccine with $146 \mathrm{~S}(2.2 \mu \mathrm{g} /$ serotype/dose $)$ these results come in agreement with previous reports $[28,30,33,40]$ who mentioned that vaccination of calves with the locally produced bivalent FMD vaccine adjuvanted with Montanide ISA 206 induced higher antibody titers than the recommended protective level
(1.5 $\log _{10}$ for SNT and $1.9 \log _{10}$ for ELISA) for both of type $A$ and $O$ as estimated by SNT and ELISA on the $4^{\text {th }}$ week post vaccination to record peak titers by the 12 week post vaccination for both types. These antibody titers remained within the protective level up to 36 weeks post vaccination in the 2 farms under study. 


\section{Conclusion}

From all the above results it is clear that the minimal protective antigenic $146 \mathrm{~S}$ content of the used FMDV serotypes should not be less than $2.2 \mu \mathrm{g} / \mathrm{dose}$ from each serotype to ensure the highest protection rate either in Guinea pig or in cattle.

\section{Authors' contributions}

HMD made the suitable dilution from vaccines, Complement Fixation test, and preparation of the monovalent vaccine, inoculate the Guinea pigs with the prepared vaccines and calculate $\mathrm{GPPD}_{50}$. EEI prepared tissue culture for 3 serotypes of FMDV inoculation, estimated total protein for each serotype, carried out adaptation of 3 FMDV serotypes in Guinea pigs, inoculating the Guinea pigs with the prepared vaccines and calculation of $\mathrm{GPPD}_{50}$, carried oute SNT on serum of Guinea pigs, wrote the manuscript and follow up the steps of publication. WMG prepared the 3 FMDV serotypes, estimated the $146 \mathrm{~S}$ and determined the lowest concentration of $146 \mathrm{~S}$ for each serotype and formulated the vaccines, made the dilution of each serotype to formulate the vaccine by using the lowest $146 \mathrm{~S}$, inoculate the Guinea pigs with the prepared vaccines and calculated $\mathrm{GPPD}_{50}$. AIH made virus titration and inactivation to each serotype using the suitable method, estimated 146S, inoculated the Guinea pigs with the prepared vaccines and calculated $\mathrm{GPPD}_{50}$. All authors read and approved the final manuscript.

\section{Acknowledgements}

Authors are thankful to Prof. Dr. Seham Abd ELRashid Director of VSVRI, Prof. Dr. Sayed Zedan Deputy of VSVRI and all members of FMD department specially Prof. Dr. Magdy Abd El-Aty head of FMD department, VSVRI. Also thanks to Prof. Dr. Mohamed Hassan Khoudier, Prof. Dr. Khayrat Abdel Mageed Elian and Prof. Dr. Mohamed Saad for reviewing this work. This work was funded by Veterinary Serum and Vaccine Research Institute, Abbasia, Cario, Egypt.

\section{Competing interests}

The authors declare that they have no competing interest.

\section{References}

1. Depa, P.M., Dimri, U., Sharma, M.C. and Tiwari, R. (2012) Update on epidemiology and control of Foot and Mouth Disease - A menace to international trade and global animal enterprise, Vet. World, 5(11): 694-704.

2. Knowles, N.J. and Samuel, A.R. (2003) Molecular epidemiology of foot-and-mouth disease virus. Virus Res.,91(1): 65-80.

3. Ko, Y.J., Jeoung, H.Y., Lee, H.S., Chang, B.S., Hong, S.M., Heo, E.J., Lee, K.N., Joo, H.D., Kim, S.M., Park, J.H. and Kweon, C.H. (2009) A recombinant protein-based ELISA for detecting antibodies to foot-and-mouth disease virus serotype Asia 1. J. Virol. Methods, 159(1): 112-118.

4. Belsham, G.J. (1993) Distinctive features of FMDV, a member of the Picorna virus family, aspects of virus protein synthesis, protein processing and structure. Progress in
Biophysics and Molecular Biology, 60: 241-260.

5. Paton, D.J., Valarcher, J.F. and Bergmann, I. (2005) Selection of foot and mouth disease vaccine strains - a review. Rev. Sci. Tech., 24(3): 981-993.

6. Cartwright, B., Brown, F. and Chapman, W. G. (1980) Serological and immunological relationships between the $146 \mathrm{~S}$ and $12 \mathrm{~S}$ particles of foot-and-mouth disease virus. Journal of General Virology, 50:369-375.

7. Aidaros, H.A. (2002) Regional status and approaches to control and eradication of FMD in the Middle East and North Africa.Rev. Sci. Tech.Off.Int. Epiz., 21 (3):451-458.

8. Knowles Nick, J., Wadsworth, J., Reid, S.M., Swabey, K.G., El-Kholy, A.A., Abd El-Rahman, A.O., Soliman, H. M., Ebert, K., Ferris, N.P., Hutchings, G.H., Statham, R.J.,King, D.P. and Paton, D.J. (2007) Foot-and-Mouth Disease Virus Serotype A in Egypt. Emerg Infect Dis., 13(10): 1593-1596.

9. FAO (2012) Foot-and-Mouth disease caused by serotype SAT2 in Egypt and Libya: a regional concern for animal health in North Africa and the Middle East. EMPRES WATCH, Vol. 25, March 2012.

10. Shawky, M., Abd El-Aty, M., Fakry, H.M., Daoud, H.M., Ehab El-Sayed, I., Wael Mossad, G., Rizk, S.A., Abu-Elnaga, H., Mohamed, A. A., Abd El-kreem, A. and Farouk, E. M. (2013) Isolation and Molecular Characterization of Foot and Mouth Disease SAT2 Virus during Outbreak 2012 in Egypt. $J$ Vet $A d v, 3(2)$ : 60-68.

11. Crowther, J.R., Reckziegel, P.O. and Prado, J.A. (1995) Quantification of whole virus particles (146S) of foot-andmouth disease virus in the presence of virus subunits (12S), using monoclonal antibodies in a sandwich ELISA. Vaccine, 13(12): 1064-1075.

12. Shiari, J., Chatchawanchonteera, A., Sinsuwongwat, W., Makarasen, P. and Sugimura, T. (1990) Estimation of 140S particles in FMD virus vaccine by using the computer analyzing system.Jap. J. Vet. Sci., 52(3): 621-630.

13. Alkan M., S. Gurcan, M. F. Sarac, Y. Gultekin, A. Arslan, E. Uzunlu, S. Akyuz and G.Aynagoz (2008) Development of a Foot and Mouth disease vaccine potency tests without conducting animal challenge experiment. The Global control of FMD - Tools, ideas and ideals - Erice, Italy 14-17 October 2008, pp.181-186.

14. OIE (2012) FMD, Chapter 2.1.5. In manual of Standard for Diagnostic Test and Vaccine, Paris, pp.77-92.

15. Richard C. Knudsen, Christopher M. Groocock, and Arthur A. Andersen (1979) Immunity to Foot-and-Mouth Disease Virus in Guinea Pigs: Clinical and Immune Responses. Infection and Immunity, 24(3): 787-792.

16. EL-Garf, E.M. (2012) Using of guinea Pigs as animal model to determine the PD50 of local oil bivalent FMD vaccine. 7th Int. Sci. Conf., Mansoura 28-30 August. pp. 797-809.

17. Black, L., Francis, M.J., Rweyemamu, M.M., Umehara, O. and Boge, A. (1985) "The relationship between serum antibody titers and protection from foot and mouth disease in pigs after oil emulsion vaccination". J. Biol. Stand., 12(4): 379-389.

18. Huang, X., Li, Y., Fang, H. and Zheng, C. (2011) Establishment of persistent infection with foot and mouth disease virus in BHK-21 cells. Virology Journal, 8: 169.

19. Reed, L.J. and Muench, H. (1938) A simple method for estimating fifty percent (50\%) end points. Amer. J. Hyg., 27: 493-497.

20. Traub, E. and Manso, I.R. (1944) Uber die herstellung complement bindender merrsch-weinehon sera fur die typen diagnose bie Maul und Klauenseuche. Zbi. Bakt. Lorig., $151: 380-381$

21. Health protection Agency (2009) Complement fixation tests. Issue no:3 Issue date 11.12.09 Issued by: standards unit, Department for Evaluations, standards and Training, page 1 of 23 .

22. Rizk, S. (2007) Studies on the preparation of an improved Foot and Mouth Disease oil vaccine. Ph. D. Thesis, University of Cairo. 
23. Killington, P.A., Stokes, A. and Hierolzer (1996) Virology Methods Manual; Chapter 4: 72-89.

24. Barteling, S.J. and Cassim, N.I. (2004) Very fast (and safe) inactivation of foot-and-mouth disease virus and enteroviruses by a combination of binary ethyleneimine and formaldehyde. Dev Biol. (Basel), 119: 449-55.

25. Ali, S.M., Abd El-Aty, M.M., Elnakashly,S.A. and ElKilany,A.S. (2009) "Inactivation of FMDV (Type O and A) by using a combination of binary ethyleneamine and Formaldehyde". 3rd Sci. Cong., Faculty of Kafr El-Sheik, pp. 962-973.

26. Doel, T.R. and Chong, W.K.T., (1982) Comparative immunogenicity of $146 \mathrm{~s}, 75 \mathrm{~s}$, and $12 \mathrm{~s}$ particles of FMDV. Arch. Virol., 73: 185-191.

27. Bartelling, A.S.J., Van Maanan, C., Yadin, H. and Anemaet, D.A.J. (1990) A Foot and Mouth Disease vaccine bank; purified inactivated antigen stored at ultra-low temperatures for the rapid preparation of double oil emulsion vaccines. Eurpean commission for control of Foot and Mouth Disease. Session of Research Group of the standing technical Committee, Lindholm, 1990, pp. 172-177.

28. Gamil, M.A. (2010) Studies on the immune response of calves vaccinated inactivated bivalent FMD virus vaccine type O1 and A Egypt 2006. M.V.Sc in Veterinary Science (virology). Benha University.

29. El-Sayed, E., Gamal El-Din, W.M.,Rizk, S.A. and Abd ElAty, M. (2012) Effect of Different Storage Temperatures on the Efficacy of the Bivalent Foot and Mouth Disease Oil Vaccine. Journal of Advanced Veterinary Research, 2:198-205.

30. Assem, A. M. (2010) Trial for preparation of bivalent oil adjuvant FMD vaccine. Ph. D Faculty of Veterinary Medicine, Department of Microbiology Alexandria University.

31. Ferreira, M.E.V. (1976) Microtitre neutralization test for the study of FMD antibodies. Bol. Centro Pan Americano de Fiebre Aftosa, 21:22-23.

32. Parida, S. (2009) Vaccination against foot- and- mouth disease virus: strategies and effectiveness Expert Rev. Vaccines 8(3): 347-365.
33. Ibrahim, E.E. (2011) Advanced studies on Foot and Mouth Disease Vaccines of sheep in Egypt. Ph D.Sc. Thesis (Infectious Diseases), Faculty of Veterinary Medicine, Cairo University, Egypt.

34. Ahmed, H.A., Salem, S.A., Habashi, A.R., Arafa, A.A., Aggour, M.G., Salem, G.H., Gaber, A.S., Selem, O., Abdelkader, S.H., Knowles, N.J., Madi, M., ValdazoGonzález, B.,Wadsworth, J., Hutchings, G.H., Mioulet, V., Hammond, J.M., King, D.P. (2012) Emergence of foot-andmouth disease virus SAT 2 in Egypt during 2012. Transbound Emerg Dis.,59(6):476-481.

35. Brown, F. (1992) New approaches to vaccination against foot-and-mouth disease. Vaccine, 10:1022-1026.

36. Motamedi Sedeh. F., Khorasani, A., Shafaee, K., Salehizadeh, M., Fatolahi, H., Arbabi, K., Daneshvari, S. and Abhari, M. (2007) Immune response of Foot and Mouth Disease Virus Type A87/IRN Inactivated vaccine by gamma irradiation on Guinea Pig in Iran, Iranian Journal of Science \& Technology, Transaction A, 31(A1): 35-41.

37. Pay, T.W.F. and Hingley, P.J. (1987) Correlation of $140 \mathrm{~S}$ antigen dose, the serum-neutralising antibody response and the level of protection induced in cattle by foot-and-mouth disease vaccines. Vaccine, 5:60-64.

38. Morgan, D.O., Bachrach, H.L. and McKercher, P.D. (1969) Immunogenicity of nanogram to milligram quantities of inactivated foot-and-mouth disease virus. Part I. Relative virus-neutralising potency in guinea pig sera. Appl Microbiol., 17(3): 441-445.

39. Barnett, P.V., Pullen, L., Warder, P. and Stathen, R. (1998) International bank for foot and mouth disease vaccine (preliminary studies on emergency foot and mouth disease vaccines formulated with montanide IMS -Immunosol-, a new concept in oil adjuvancy. European Commission for the Control of FMD, Aldershot, United Kingdom, 14-18 September 1998, Appendix 37: 268-271.

40. El-Sayed, E., Mossad, W., Ali, S.M. and Shawky, M. (2012) Studies on the duration of immunity induced in cattle after natural FMD infection and post vaccination with bivalent oil vaccine, Vet World, 5(10): 603-608. 